\title{
A Realist Perspective on AI-era Public Management
}

\section{An Analysis of Mechanisms, Outcomes and Challenges of Al Solutions in the Public Sector}

\author{
Adegboyega Ojo \\ Insight Centre for Data Analytics \\ NUI Galway \\ Galway, Co. Galway, Republic of \\ Ireland, \\ adegboyega.ojo@nuigalway.ie
}

\author{
Fatemeh Ahmadi Zeleti \\ Insight Centre for Data Analytics \\ NUI Galway \\ Galway, Co. Galway, Republic of \\ Ireland, \\ fetemeh.ahmadizeleti@nuigalway.i
}

\author{
Sehl Mellouli \\ Faculty of Business \\ Administration Université Laval \\ Québec, Québec, Canada, \\ sehl.mellouli@fsa.ulaval.ca
}

\begin{abstract}
Recent years have witnessed a number of significant ideas and approaches to addressing the shortcomings of the New Public Management paradigm. Three of these recent ideas, which include Digital Era Governance, Public Value Management, and New Public Governance, emphasise partnerships collaboration and engagement of citizens; performance governance and innovation and recognize the transformational potentials of digital technologies. Artificial Intelligence (AI) is one of the digital technologies attracting the greatest interest in public administration in terms of its potential impact. There are already a number of reports on how AI is being deployed in the public sector with good outcomes. By employing a realist review approach, this study investigates the specific mechanisms across post-NPM, organisational, individual and innovation contexts which are associated with positive outcomes from AI initiatives in the public sector. The study further examined the specific applications of AI initiatives within Post-NPM agendas. Our findings provide some empirical evidence for a better understanding of the conditions and where to target AI-based solutions in post-NPM context for positive outcomes.
\end{abstract}

\section{CCS CONCEPTS}

- Artificial Intelligence - Information Systems - Machine Learning

\section{KEYWORDS}

AI and Public Sector, Post-New Public Management, Realist Evaluation, AI Adoption in Government

\footnotetext{
Permission to make digital or hard copies of all or part of this work for personal or classroom use is granted without fee provided that copies are not made or distributed for profit or commercial advantage and that copies bear this notice and the full citation on the first page. Copyrights for components of this work owned by others than ACM must be honored. Abstracting with credit is permitted. To copy otherwise, or republish, to post on servers or to redistribute to lists, requires prior specific permission and/or a fee. Request permissions from permissions@acm.org.

dg.o 2019, June 18-20, 2019, Dubai, <, United Arab Emirates

(c) 2019 Association for Computing Machinery.

ACM ISBN 978-1-4503-7204-6/19/06...\$15.00

https://doi.org/10.1145/3325112.3325261
}

\section{ACM Reference format:}

Adegboyega Ojo, Fatemeh Ahmadi Zeleti and Sehl Mellouli. 2019. A Realist Perspective on AI-era Public Management: An Analysis of Mechanisms, Outcomes and Challenges of AI Solutions in the Public Sector. In Proceedings of dg.o 2019: 20th Annual International Conference on Digital Government Research (dg.o 2019), June 18-20, 2019, Dubai, <, United Arab Emirates. ACM, New York, NY, USA, 14 pages. https://doi.org/10.1145/3325112.3325261

\section{ACM Reference format:}

Adegboyega Ojo, Fatemeh Ahmadi Zeleti and Sehl Mellouli. 2019. A Realist Perspective on AI-era Public Management: An Analysis of Mechanisms, Outcomes and Challenges of AI Solutions in the Public Sector. In Proceedings of dg.o 2019: 20th Annual International Conference on Digital Government Research (dg.o 2019), June 18, 2019, Dubai, United Arab Emirates. ACM, New York, NY, USA, 12 pages. https://doi.org/10.1145/3325112.3325261

\section{Introduction}

Public management and governance scholars largely agree on the need for new paradigms to succeed the New Public Management (NPM), which drove reform programmes in government administration between 1985 and 2002 [1]. This sentiment has grown with developments and evolution in digital government in which information technology (IT) is central to the transformation of how government institutions work internally and how they engage stakeholders, in particular citizens and businesses externally for decision-making and services delivery. According to NPM critics, this approach and earlier ones failed to consider the critical importance of IT in their respective theories [2]. According to Dunleavy et al. [2], contemporary changes in public management and governance systems are IT-based. They claim that these technological influences are not necessarily directly deterministic but expressed via a wide range of cognitive, behavioural, organisational, political and cultural changes linked to information systems [2].

Consequently, recent public management paradigms such Digital Era Governance (DEG), Public Value Management (PVM) and New Public Governance (NPG) explicitly seek to harness the affordances of IT or digital technologies [3]. These recent 
frameworks, in general, seek to exploit digital technologies for supporting greater openness, collaborations and partnerships, engaging citizens, performance governance and core integrated service delivery [3]-[5]. For example, the defining features of the so-called DEG 2.0 (the second wave of DEG) includes the adoption of open data, social media and Web 2.0 applications, cloud computing to drive transparency and its shared services objectives [1]. In fact, Clarke \& Margetts argued in [6] that the use of open and big data is supporting unprecedented levels of mutual government-citizen understanding, and in turn driving improvements in public policy and services.

Artificial Intelligence (AI) is one of the emerging technologies that is attracting most interests by governments and public administrations in different parts of the world [7]. With the considerable maturity of AI over the past few years, the public sector and societies are looking to embrace the opportunities it provides and address the collateral risks it poses [8]. The European AI strategy asserts the transformational power of AI and the potential to improve public services [9]. Capgemini estimates that AI applications in the public sector will create a savings of between $€ 2$ and 5 billion globally and $1.93 \%$ point growth in world GDP by 2025 [10]. Apart from the EU region, individual countries such as the UAE and Germany are also developing their national AI strategy [8], [11].

While the stock of AI research in digital government and public administration is growing steadily [12], research examining if and how AI applications are truly shaping Public management practices as advanced by the recent paradigms are to our knowledge not available. Such studies are critical for better understanding of concrete mechanisms and associated contextual conditions for which the adoption and use of AI applications in a post NPM era produce positive outcomes.

This article examines the application of AI solutions in the context of recent public management and governance paradigms including DEG, PVM, and NPG. Specifically, we are interested in understanding the contextual mechanisms for effective adoption of AI solutions in these post-NPM contexts, the specific outcomes obtained, challenges faced and the specific post-NPM area targeted. The rest of the paper is organised as follows. Section 2 provides the conceptual foundation for the study, followed by the methodology in Section 3. The findings are presented in Section 4 and discussed in Section 5. We close in Section 6 with reflections on our findings and prescribe areas for future work.

\section{Conceptual Foundation}

We develop here the conceptual framework for exploring the context, mechanisms and outcomes of AI solutions in the public sector within a realist evaluation approach. As a first step, we establish the different contexts for AI applications in a Post-NPM era. This is achieved through an integrative treatment of three of the major post-NPM paradigms - DEG, PVM and NPG. As a second step, we examine the fundamental affordances of Artificial Intelligence in general and for public management in particular. This is done by identifying specific AI related methodologies and tools. Thirdly, we describe a "realist evaluation framework" for describing the various cases of AI applications in the public sector reviewed in our work.

\subsection{Integrating Post-NPM Approaches}

The New Public Management (NPM) remains the most wellknown reform paradigm in public management and governance [1]. NPM as a paradigm for reforming government institutions is closely associated with ideas of managerialism-style of the private sector, strong customer service orientation and use of less hierarchical organisational control mechanisms [2]. This paradigm is characterised by three features namely: disaggregation by splitting up large public organisation hierarchies; competition enabling multiple forms of provisions to be developed among providers and incentivisation characterised by pecuniary-based specific performance incentives for staff [2]. While NPM reform programmes have been institutionalised in many governments across the world, the fragmentation resulting from its implementation has led to major policy disasters [2]. In fact, radical NPM models have also specifically worked against successful adoption digital technologies into government [6] as IT operations of government were outsourced to global IT services provider. There are also claims that NPM reduced the citizens' capacity to engage and interact with government.

To address NPM shortcomings, governments have rolled back several NMP initiatives and adopted new a mindset to public management and governance which places available digital technologies at its core. Three leading successors of the NPM paradigm are Digital Era Governance (DEG), Public Value Management (PVM) and New Public Governance (NPG) [3]. These three public management approaches provide alternative but somewhat complementary conceptualisations for contemporary public sector management. A common theme across these three ideas is the centrality of digital technologies.

Digital Era Governance - proposed by Dunleavy and his collaborators aims to address some of the reported unintended negative outcomes from NPM by focusing on reintegrating functions in government sphere (re-integration), adopting holistic and needs-oriented structures (need-based holism) and intensifying digitalisation of administrative processes (digitalisation) [2]. Unlike in NPM, DEG highlights the influence and impact of the evolutions in IT and digital technologies on public sector management. Following the first wave of DEG (2002 - 2010), the second wave of DEG (from 2010 to date) has been characterised in [1], [3] by 1) transparency, 2) the use of social media and 3) establishment of shared service centres. Transparency initiatives in this context are associated with promoting open access to government information through freedom of information acts (FOIA), providing more information on a specific policy field or programme of high public interest (so-called targeted transparency) and publication of open government data. The use of social media by government here is aimed at better engaging citizens to crowdsource ideas on policies and programmes and opening up more channels for citizens to express their opinions about government services and programmes. Shared service centres are aimed at achieving more 
efficient and effective government and also enabling the recentralisation of many common tasks that were previously delegated to individual organisations (in response to NPM principles of specialisation).

Public Value Management (PVM) - At the core of PVM is the achievement of public value [13]. In this paradigm, public value is more than a summation of individual preferences of the users of public services. What is accepted as public value is collectively built through deliberations involving elected representatives and appointed government officials. In addition, PVM hinges on a clear understanding of public interest, the nature of public service ethos, the role of public managers and contributions of democratic processes [14]. According to [3], PVM is characterised by three elements: Strategy-making for public value creation; performance governance and Innovation. In the context of strategy-making, PVM maintains that public managers are in a so-called strategic-triangle between legitimizing and authorizing environment, an organising environment in the area of focus and environment of results (efforts to produce results or public value) [3]. Strategies in the context of PVM is differentiated from NPM in terms of a) its post-competitive orientation, b) its focus on relationships and not only on results and c) its preference for the collective interest expressed over the simple aggregation of individual preferences. The second element of performance governance focuses on long term outcomes and how to balance outputs with outcomes. In addition, performance management in PVM is integrated with the institutional framework and wider governance structures. Furthermore, performance management relies on the use of data, in particular, real-time data for managing and governing public organisations. The third element - innovation, involves having an environment that enables public managers to be creative and to think out-of-the-box. Innovation in this context could be at the individual or organisational levels. However, the innovation environment in PVM conceptualisation is different from the traditional innovation environment in the private sector. For instance, innovation is valued in the PVM as a means itself even though the end products are also valuable. Benefits from innovation are also shared not only by the associated public manager and organisation but by the whole public sector if the innovation is emulated.

New Public Governance - this paradigm of public service delivery is deeply rooted within institutional and network theory [15]. It considers both a situation where multiple interdependent actors contribute to the delivery of public services as well as the situation in which multiple processes inform policy-making systems. Three elements of NPG are identified in [3] including network and collaboration, public-private partnerships and engagement of citizens through "public" making. In the area of network and collaboration, NPG considers that no single organisation is capable of handling the type of public policy challenges facing governments, making cooperation, collaboration, and partnering necessary [3]. Thus, NPG focuses attention on partnership, networks, joined-up services and new ways of working. Co-production with citizens is another aspect of networking and collaboration. In the area of public-private partnership (PPP), both public and private sector share risks and resources to provide value over time. PPP is institutionalised cooperation arrangement between private-sector and publicsector actors [15]. This mechanism also breeds innovation since partners come from different backgrounds [3]. The third element on engaging citizen is linked to recent phenomena of citizens' use of social media to express themselves and influence issues. It also covers all forms of e-activisms by citizens on a range of public issues. Dialog on performance management is becoming a key feature of citizen activism on social media. An important aspect of this engagement related to the concept of publicmaking, a phenomenon in which public managers create different citizen groups ("publics") with specific needs and interests. A summary of the features of the Post-NPM paradigms is provided in Table 1 .

Table 1: Elements of post-NPM paradigms.

\begin{tabular}{|c|c|c|}
\hline $\begin{array}{l}\text { Digital Era Governance } \\
1 \& 2 \text { (DEG) }\end{array}$ & $\begin{array}{l}\text { Public Value } \\
\text { Management } \\
(\mathrm{PVM})\end{array}$ & $\begin{array}{l}\text { New Public } \\
\text { Governance (NPG) }\end{array}$ \\
\hline $\begin{array}{l}\text { Transparency } \\
\text { Social Media } \\
\text { Shared-service Centre } \\
\text { Reintegration } \\
\text { Digitisation } \\
\text { Need-based holism }\end{array}$ & $\begin{array}{l}\text { Strategy- } \\
\text { making } \\
\text { Performance } \\
\text { Governance } \\
\text { Innovation }\end{array}$ & $\begin{array}{ll}\text { Networks and } \\
\text { Collaboration } \\
\text { Public-Private } \\
\text { Partnerships } \\
\text { Engaging active } \\
\text { citizens }\end{array}$ \\
\hline
\end{tabular}

\subsection{AI \& Its Affordances for Public Management}

According to the European AI strategy, Artificial Intelligence refers to systems that display intelligent behaviour by analysing their environment and taking action - with some degree of autonomy - to achieve specific goals [9]. Much earlier, Feigenbaum described AI as concerned with constructing machines (usually programs for general-purpose computers) which exhibit behaviours such that if observed in human activity, we would label the behaviour "intelligent"[16]. Simons in his well-known work [17], described AI as a part of computer science, psychology and cognitive science. He further described $\mathrm{AI}$ as dealing with phenomena associated with computers performing tasks that would be considered as requiring intelligence if it were performed by people. AI represents the science that aims to give a machine the ability to perceive, reason and act as humans [17].

Minsky described five important classes of problems that could be associated with intelligent problem-solving machines or AI to include search, pattern recognition, learning, planning and induction [18]. Feigenbaum identified AI systems exemplars to include General problem-solver, game-playing programs, question-answering machines, simulation of cognitive processes and inductive systems [16]. The Association for Computing Machinery (ACM) Computing Classification System (CCS) taxonomy ${ }^{1}$ has identified a number of methodologies under

\footnotetext{
${ }^{1}$ https://dl.acm.org/ccs/ccs.cfm?id=10010178\&lid=0.10010147.10010178
} 
Artificial Intelligence including natural language processing, knowledge representation and reasoning, planning and scheduling, search methods, control methods, distributed intelligence and computer vision. Recently, Eggers et al. in their report entitled "AI-augmented Government" listed AI technologies to include [12]: machine learning, computer vision, speech recognition, natural language processing and robotics. The different typologies is presented in Table 2.

Emerging applications of $\mathrm{AI}$ in the public sector suggests that there are at least five categories of AI use in the context of citizen services [19]. These include 1) answering questions; 2) filling out and searching documents, 3) routing requests, 4) translation and 5) drafting documents. In [12], three core applications of AI in government include: 1) robotic and cognitive automation, enabling the shifting of human labour to high-value work through technologies such as Robotic Process Automation, 2) enabling cognitive insights through better predictive capabilities; and 3) Cognitive engagement through answering citizen queries.

According to [12], AI-based applications are already having impacts in government and "could potentially reduce backlogs, cut cost, overcome resource constraints, free workers from mundane tasks, improve the accuracy of projections and inject intelligence into scores of processes and systems ... ". Specifically, AI-based technology can speed up tasks by as much as $200 \%$ with high investment and potential cost savings between 3.3 billion USD and 41 billion USD.

Table 2: AI problems, methodologies \& technologies.

\begin{tabular}{|c|c|c|}
\hline $\begin{array}{ll}\text { Minsky } & \& \\
\text { Feigenbaum } & \\
\text { AI Problems } & \\
\end{array}$ & $\begin{array}{l}\text { Eggers et al. } \\
\text { AI Technologies }\end{array}$ & $\begin{array}{l}\text { ACM CCS } \\
\text { AI Methodologies }\end{array}$ \\
\hline $\begin{array}{l}\text { Search, } \\
\text { Pattern } \\
\text { recognition, } \\
\text { Learning, } \\
\text { Planning, } \\
\text { Induction, } \\
\text { General } \\
\text { problem-solving, } \\
\text { Game-playing, } \\
\text { Question- } \\
\text { answering and } \\
\text { Simulation of } \\
\text { cognitive } \\
\text { processes }\end{array}$ & $\begin{array}{l}\text { Machine learning, } \\
\text { Computer vision, } \\
\text { Speech } \\
\text { recognition, } \\
\text { Natural language } \\
\text { processing, } \\
\text { Robotics }\end{array}$ & $\begin{array}{l}\text { Machine Learning* } \\
\text { Natural language } \\
\text { processing, } \\
\text { Knowledge } \\
\text { Representation and } \\
\text { Reasoning, } \\
\text { Planning } \\
\text { scheduling, and } \\
\text { methods, search } \\
\text { methods, distributed } \\
\text { intelligence } \\
\text { computer vision }\end{array}$ \\
\hline
\end{tabular}

\subsection{A Realist review framework for AI applications in the} Post-NPM Contexts

With steadily growing accounts of completed AI initiatives in the public sector, traditional review and evaluation of these initiatives often reduce the success to a binary yes or no outcome [20]. Unfortunately, such simple characterisation are not so useful for further research and practitioners seeking to replicate the solutions in different contexts. The realist evaluation or review framework is an explanatory model that links the context, mechanisms, and outcome patterns discovered during the implementation of a project [20]. Essentially, the realist review is an explanatory framework which enquires about "what works for whom in what circumstances" [21]. Originally designed for social programmes, the realist evaluation focuses on the contexts rather than programs as the subject matter of interest and proposes that contexts are relatively enduring and are what programmes aim to transform (rather than reproduce) by activating various structural, cultural, agential and relational mechanisms to produce outcomes [22]. Here, we are interested in the specific mechanisms that are directly responsible for obtaining positive outcomes (such as those highlighted in Section 2.2) in cases where AI solutions have been deployed. Thus our interest goes beyond obtaining "factors" that are typical of adoption models.

There are three important elements of a realist review results, the context, mechanism and outcome [22]. The context is the prevailing conditions which comprise material resources, social structures, including the conventions, rules, and systems of meaning in terms of which reasons are formulated' [22]. Context also covers pre-existing features of a locality, situation or microsystem into which programmes are introduced [20]. Mechanisms describe what it is about the interventions that bring about effect [20]. It also includes the processes through which subjects interpret and act on the intervention. Outcomes are Intended and unintended consequences resulting from activation of the various mechanisms. Unlike factors which merely contribute to outcomes, mechanisms by nature have causal relationships with outcomes.

In the work of Wisdom et al. [21], they applied the realist framework approach to capture how technology adoption works, why and for whom? Their work provides a rich set of mechanisms that could be considered across different contexts when considering the adoption and use of technologies. Specifically, they identified four different levels of contexts after a detailed systematic review of literature of several technology adoption theories [21]: 1) socio-political and external influence; 2) organisational characteristics; 3) innovation characteristics, and 4) staff/individual characteristics. Each of these four levels presents mechanisms for enabling the adoption of technologies. Mechanisms for socio-political and external environment influence could be further structured into the external environment, government policy and regulation, incentives to improve service delivery and linkages between systems outside an organisation. Organisational characteristics comprise absorptive capacity; availability of leadership and champion of innovation; access to external networks of innovation developers and consultants; norms, values, the culture of the organisation; its operational size and structure; as well as training readiness and efforts. The individual characteristics comprise attitudes, motivations and readiness towards quality improvement and reward; feedback on execution, awareness, knowledge/skills, competence, affiliation with organisational culture. Finally, the innovation characteristics include complexity, relative advantage and observability; cost-efficacy and feasibility, evidence and 
compatibility; innovation fit with users' norms and values and trialability, and ease of use. We show in Figure 1 a realist review framework based on Wisdom's et al. [21] four contexts designed for this study. The model shows the mechanisms leading to positive (or negative outcomes) of AI innovation in the public sector are associated with four different contextual elements including prevailing Public Management, characteristics of the adopting agency, characteristics of individuals concerned with the management and use of the AI solutions and the characteristics of the $\mathrm{AI}$ innovation under consideration.

\section{Methodology}

This study is a systematic review of completed AI initiatives in the public sector using the realist review framework described in Section 2.3. Our goal is to contribute to a better understanding of why and how AI innovations produce the desired positive outcomes in government particularly in the context of modern public management practices. We must stress that our goal is not to carry out a comprehensive realist evaluation of AI initiatives in post-NPM contexts in the traditional sense. Rather our intention is to adopt a realist approach in uncovering an initial set of theories (or propositions) that could serve as a basis for a future comprehensive realist evaluation based on a variety of evidence and data sources.

\subsection{Research Objectives}

This study aims to answer two basic questions related to the adoption of $\mathrm{AI}$ in the public sector:

R1. What are the mechanisms, outcomes \& challenges associated with AI use in the public sector?

R2. To what extent are AI solutions implemented within postNPM initiatives?

To answer question R1, we determine the nature of AI technologies used, the specific post-NPM context in which the technology is deployed and specific organisational and individual characteristics associated with the deployment if available. In addition, we determine the challenges reported during the implementation of AI across these cases. For R2, we examine the specific post-NPM themes found in our reviewed cases and determine the degree to which these themes feature. We will also highlight the degree of convergence we observe in the three post-NPM paradigms in terms of co-occurrence of these themes across cases.

\subsection{The Review Process}

We adopt the basic steps prescribed for a realist review [20]. The steps in our review process include:

Develop a working theory - this step which is to guide the enquiry was accomplished by carrying out a cursory review of a small number of key publications and reports on $\mathrm{AI}$ in the public sector and detailed analysis of the post-NPM paradigms. After this step, we adopted the working theory that "AI-based solutions deployed in post-NPM environments produce positive outcomes for stakeholders"

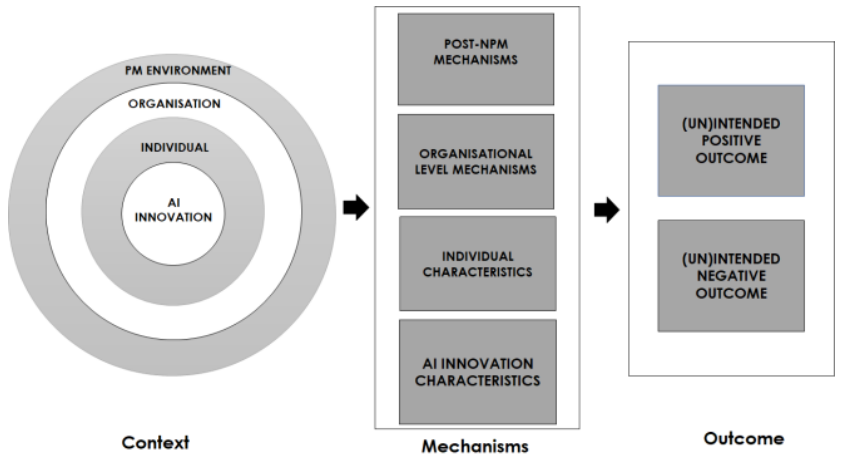

Figure 1: The Realist Review Framework for the Study.

Collect qualitative data systematically - Guided by the theory and conceptual framework we describe in Fig. 1, we searched for reports describing AI initiatives in the public sector with sufficient details with respect to our conceptual framework. We describe this step in more details in Section 3.3.

Analysis of collected data - the collected reports and literature were analysed to identify specific cases. The cases were coded and added to the dataset of cases with a unique ID. Part of the coding is based on the elements of Post-NPM paradigms (Table 1), the AI problems, methodologies and technologies (Table 2). Details are provided in Section 3.3.

Refinement of Context-Mechanism-Outcome model - We summarise our coded dataset of cases into an elaborated form of the CMO model in Figure 1. In the refined model, specific mechanisms found in the cases are grouped under the appropriate headings associated with specific contexts (see Section 4.3).

Synthesis of the CMO Configurations as a refinement of initial theory - finally, we refine the contents of the model developed in step 4 to produce more concrete theories (or propositions) on adoption and use of AI in the public sector. These are discussed in Section 4.3

\subsection{Data Collection \& Analysis}

Documents containing reports on cases of AI deployment in government was collected by searching the Scopus bibliographic database and using the Google search engine with the following keyword combinations: "AI in government", "AI in public sector", "AI for public administration", "Application of AI in government", and "Public Administration Framework and AI". From the initial set of documents, we reviewed the abstracts and summaries of the retrieved documents to eliminate irrelevant ones. For the second stage of filtering, we did a more detailed examination of the reports to ensure that the report on completed projects (due to the goal of our study and approach) and also ensured that the reports provided detailed contextual information of interest. After the second stage of filtering, we ended up with the 23 cases. For each case, we established the coded the following aspects: 1) the public management and governance sector - PMG Aspect; 2) the AI method used in the case (AI Mechanism - Method), coded using ACM CCS AI 
methodology in Table 2, 3) the specific AI technology employed in the case - AI Mechanism - Technologies, coded directly from the description of the technology; 4) the reasons for deploying AI - Objectives; 5) the public management and governance context - PMG Mechanism; 6) the post-NPM initiative coded based on Table 1 - related Post-NPM Feature. The coding and annotation of the cases were done by one of the authors and was verified by another author independently. Disagreements were resolved through discussion to arrive at unanimous decisions. Most of the cases (18) we found were associated with Federal and State institutions in the United States. Three cases were from Europe (the United Kingdom, The Netherlands and Portugal). Three cases were also associated with Asia (Hong Kong, Philippines and Singapore). Finally, one of our cases was associated with Canada.

\section{Findings}

We describe here our findings with respect to our two research questions, presented in Sections 4.1 and 4.2 respectively. We provide a synthesis of our findings or propositions in Section 4.3.

\subsection{Mechanisms, Outcomes \& Challenges}

4.1.1 What kinds of mechanisms were employed? First, from our data, we observe that the sectoral context for AI applications in the public sector includes citizen enquiries, public health and safety, emergency management, internal operations, transport management and immigration service. Citizen enquiry is the most common application area for AI in public management in our study. This is followed by internal operations (e.g. decision making and public health and safety (e.g. detection of fire safety violation). Figure 2 provides a summary of the sectoral context for AI applications in the public sector.

In terms of the specific AI mechanisms, machine learning and natural language processing standout as the two most common AI methods in use. Machine learning is used mainly for developing predictive systems (or analytics) whereas natural language processing methods are used mainly for the development of chatbots to support citizen enquiry services. Figure 3 provides the AI mechanisms found in our cases.

4.1.2 What specific outcomes were obtained? Several outcomes (albeit similar) were reported across our 23 cases as summarised in Table 4. The most common outcomes reported from the application of $\mathrm{AI}$ is the increased process and task automation and greater automation of work processes. Eight (8) out of the 23 reported these two similar automation outcomes. Another reported outcome is easier access to and greater efficiency of citizen enquiry services (about 3 cases). The other reported outcomes are shown in Table 4.

4.1.3 What specific challenges were reported? The challenges reported crosses technical, organisational and individual contexts (Table 5). At the organisation level, challenges include the capacity to design goal-based and citizen-centric AI initiatives; limited staff knowledge about machine learning and
AI, limited capacity to handle a large amount of data and maintaining privacy policies and protection mechanisms in place. At the individual level, not having the positive attitude to the use of AI is an obstacle. At the technical level, the AI systems produce poor predictive results and fail from time to time.

\subsection{AI support for post-NPM paradigms}

We now turn our attention to the second research question on the extent to which AI deployment is done in the context of post-NPM paradigms. First, a cursory look at Table 2 shows that post-NPM mechanisms of DEG and PVM were associated with AI deployment in the public sector. Elements of PVM (Innovation) were found in all 23 cases. We also found that 15 of our cases (see Fig. 4) were associated with both DEG \& PVM mechanisms. The strong co-enactment of DEG/PVM may provide some evidence of convergence these to two conceptual approaches to contemporary public management. We also observe from our cases, AI is yet to be deployed in the NPG context. Figure 5 provides specific post-NPM mechanisms found in the cases (obtained by summarising the related post-NPM feature in Table 3). Overall, AI deployments appear to be implemented so far within two of post-NPM initiatives specifically, $P V M$ and DEG initiatives.

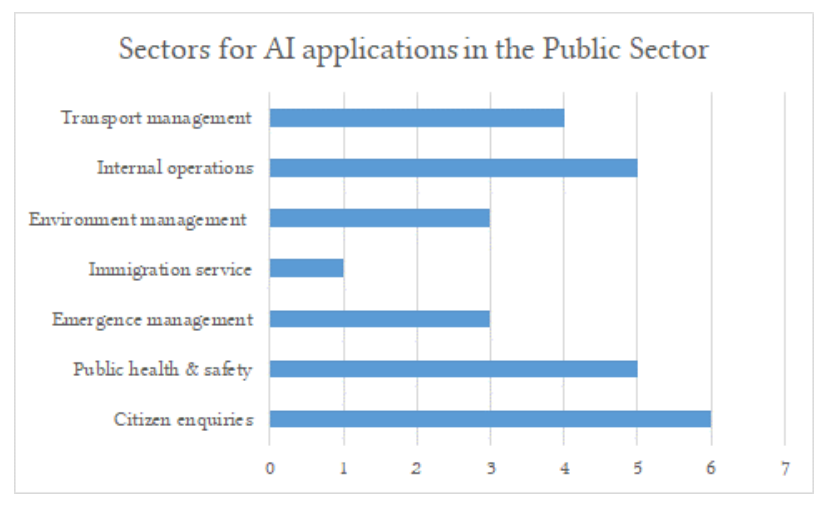

Figure 2: Sectoral context for AI applications.

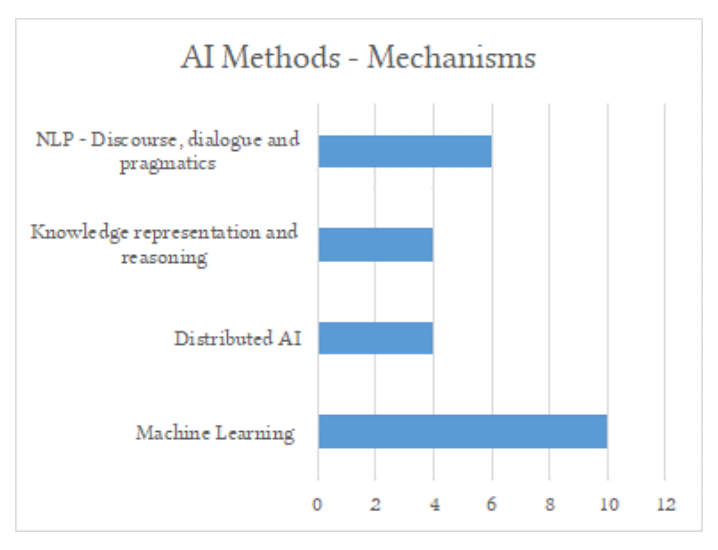

Figure 3: AI mechanisms from cases. 
Table 3: Description of cases of AI applications in the public sector.

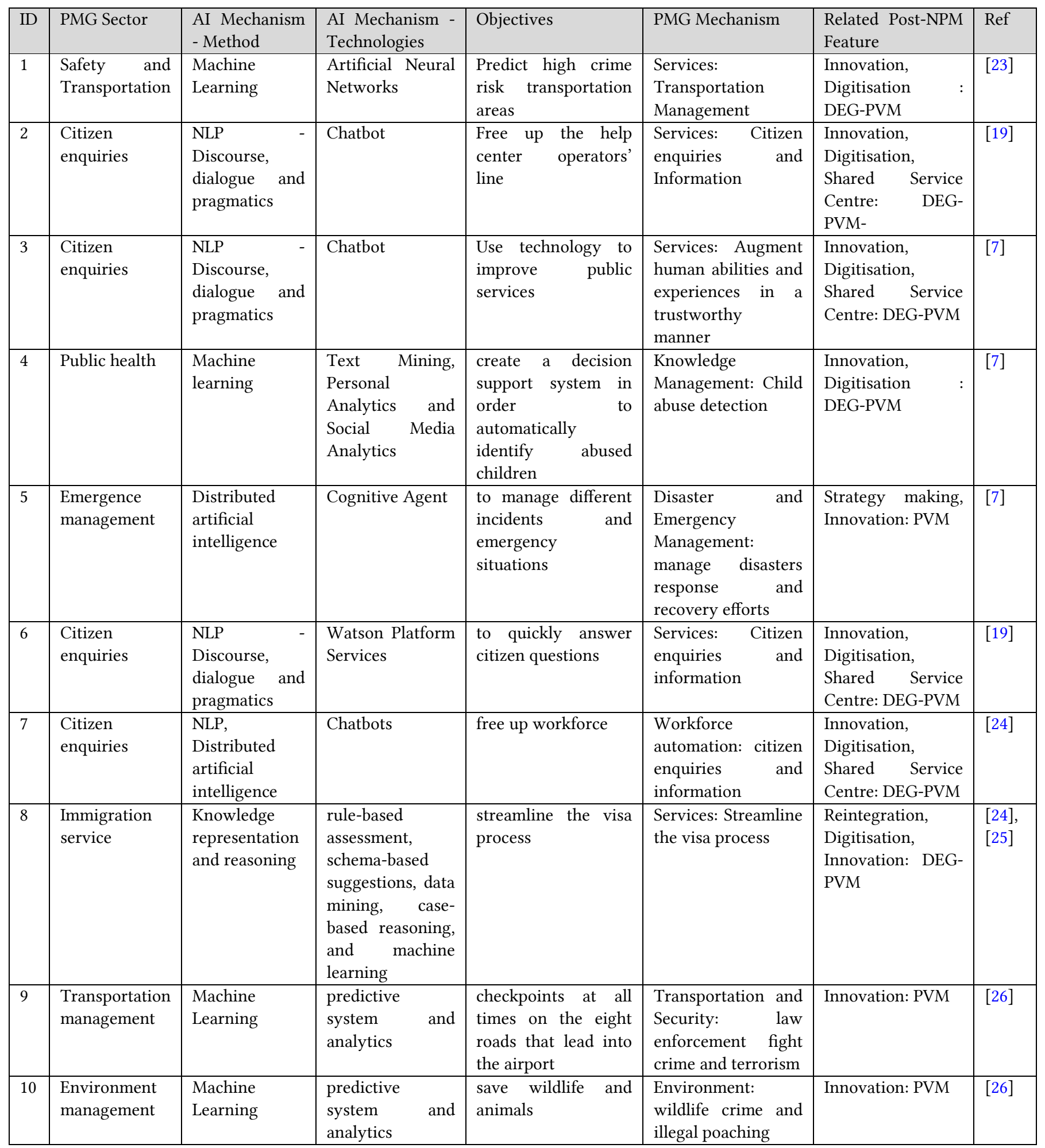




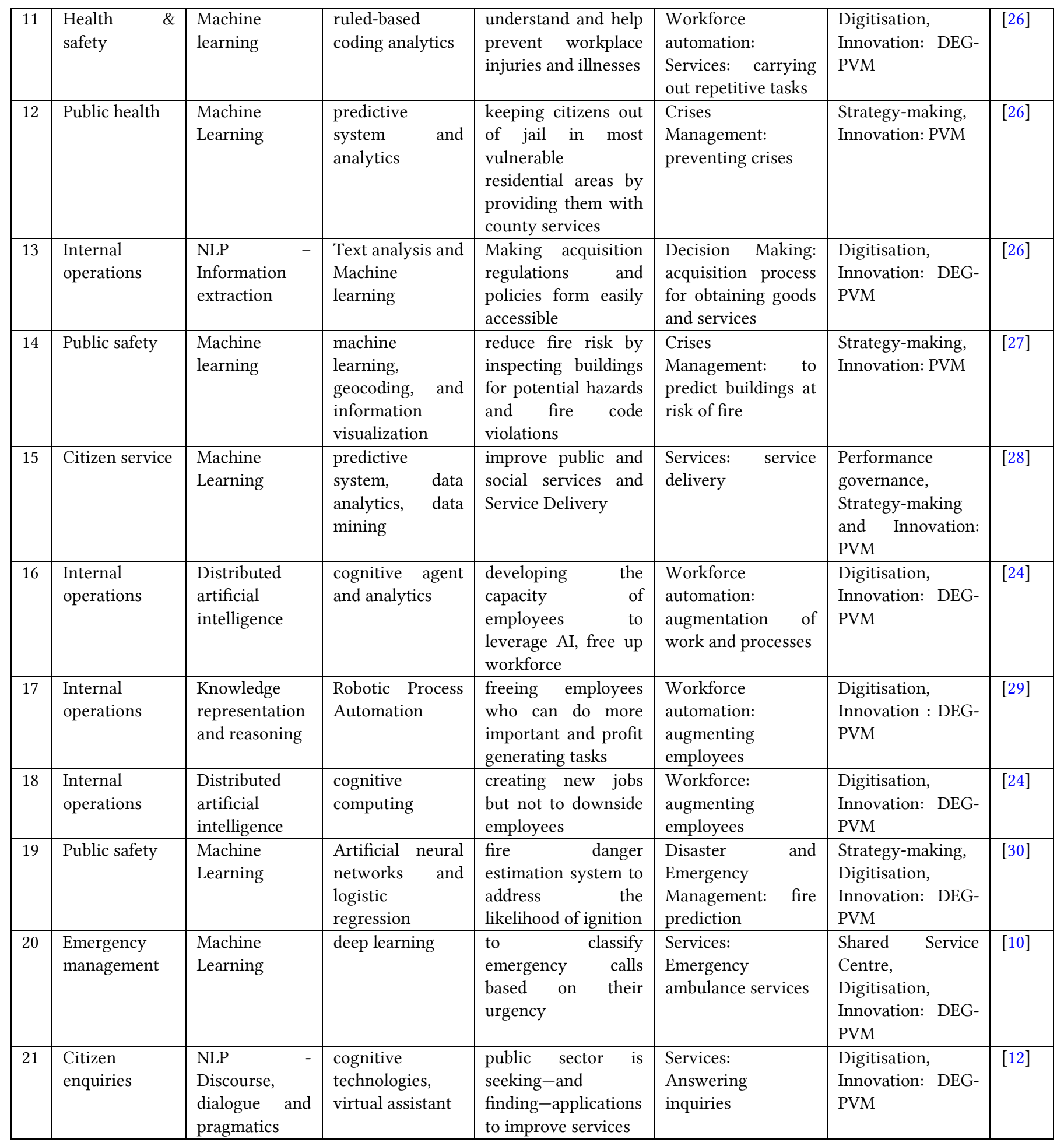




\begin{tabular}{|c|c|c|c|c|c|c|c|}
\hline 22 & $\begin{array}{l}\text { Internal } \\
\text { operations }\end{array}$ & $\begin{array}{l}\text { Knowledge } \\
\text { representation } \\
\text { and reasoning }\end{array}$ & $\begin{array}{l}\text { Robotics and } \\
\text { cognitive } \\
\text { automation, } \\
\text { Robotic process } \\
\text { automation, } \\
\text { cognitive } \\
\text { insights, and } \\
\text { cognitive } \\
\text { engagement }\end{array}$ & $\begin{array}{l}\text { ease some of the } \\
\text { personnel challenges } \\
\text { facing many } \\
\text { governments- most } \\
\text { notably, recruiting } \\
\text { younger, tech-savvy } \\
\text { workers }\end{array}$ & $\begin{array}{lr}\text { Task automation: } \\
\text { replicate human } \\
\text { actions } \\
\text { judgment, freeing } \\
\text { people from manual } \\
\text { tasks }\end{array}$ & $\begin{array}{l}\text { Digitisation, } \\
\text { innovation: DEG- } \\
\text { PVM }\end{array}$ & {$[12]$} \\
\hline 23 & $\begin{array}{l}\text { Transportation } \\
\text { management }\end{array}$ & $\begin{array}{l}\text { Knowledge } \\
\text { representation } \\
\text { and reasoning }\end{array}$ & $\begin{array}{l}\text { sensors and } \\
\text { intelligent } \\
\text { systems }\end{array}$ & $\begin{array}{l}\text { Predictive } \\
\text { capabilities }\end{array}$ & $\begin{array}{l}\text { Services: real-time } \\
\text { tracking }\end{array}$ & $\begin{array}{l}\text { Strategy-making, } \\
\text { Innovation: DEG- } \\
\text { PVM }\end{array}$ & [31] \\
\hline
\end{tabular}

Table 4: Outcomes of AI initiatives.

\begin{tabular}{|l|l|}
\hline \multicolumn{1}{|c|}{ ID } & Outcome \\
\hline 1 & Improved transportation service and safety \\
\hline $2,3,6,21$ & $\begin{array}{l}\text { Greater access and efficiency of citizen enquiry } \\
\text { services }\end{array}$ \\
\hline 4 & Identifying hidden problems in public records \\
\hline 5 & More efficient government operation \\
\hline 8 & Efficient task and work automation \\
\hline 9,10 & Increased efficacy of security threats identification \\
\hline $11,16,17$, & Efficient process and task automation \\
18 & Greater automation of work processes \\
\hline $16,17,22$, & \\
\hline 23 & Greater social programmes efficacy \\
\hline 12 & $\begin{array}{l}\text { Enabling better decision-making and anomaly } \\
\text { detection in services }\end{array}$ \\
\hline 13,14 & More effective risks identification \\
\hline 19 & Better service planning and intervention \\
\hline 20 & Improved service time and quality \\
\hline
\end{tabular}

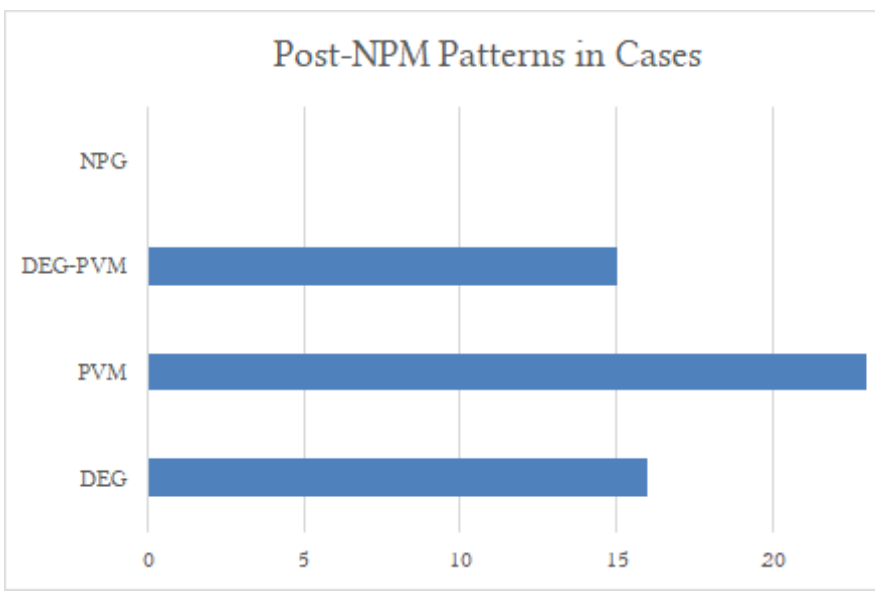

Figure 4: Patterns of Post-NPM Themes in Cases.

\section{Table 5: Challenges faced in AI initiatives.}

\begin{tabular}{|l|l|}
\hline ID & \multicolumn{1}{|c|}{ Challenges/obstacles } \\
\hline 2 & $\begin{array}{l}\text { How to make AI programmes goals-based and citizen- } \\
\text { centric program; how to be data-prepared and how to } \\
\text { handle privacy; and mitigate ethical risks }\end{array}$ \\
\hline 4 & $\begin{array}{l}\text { Handling and managing unstructured free text for AI } \\
\text { initiatives }\end{array}$ \\
\hline 7 & AI systems fail from time to time \\
\hline 10 & Modifying the existing AI software to serve the purpose \\
\hline 11 & Staff's knowledge about machine learning and what it does \\
\hline 12 & Poor predictive performance of AI system \\
\hline 13 & $\begin{array}{l}\text { Managing large amount of data involved in the AI } \\
\text { application }\end{array}$ \\
\hline 16 & Limited capacity of employees to leverage AI capabilities \\
\hline 18 & $\begin{array}{l}\text { How to educate employees on the adoption of AIs as } \\
\text { support for their jobs and how to reassure employees that } \\
\text { they are still needed even with the AI system }\end{array}$ \\
\hline 23 & $\begin{array}{l}\text { How to maintain privacy protection in place without } \\
\text { defying public records laws, how to obtain post-pilot } \\
\text { program resources? }\end{array}$ \\
\hline
\end{tabular}

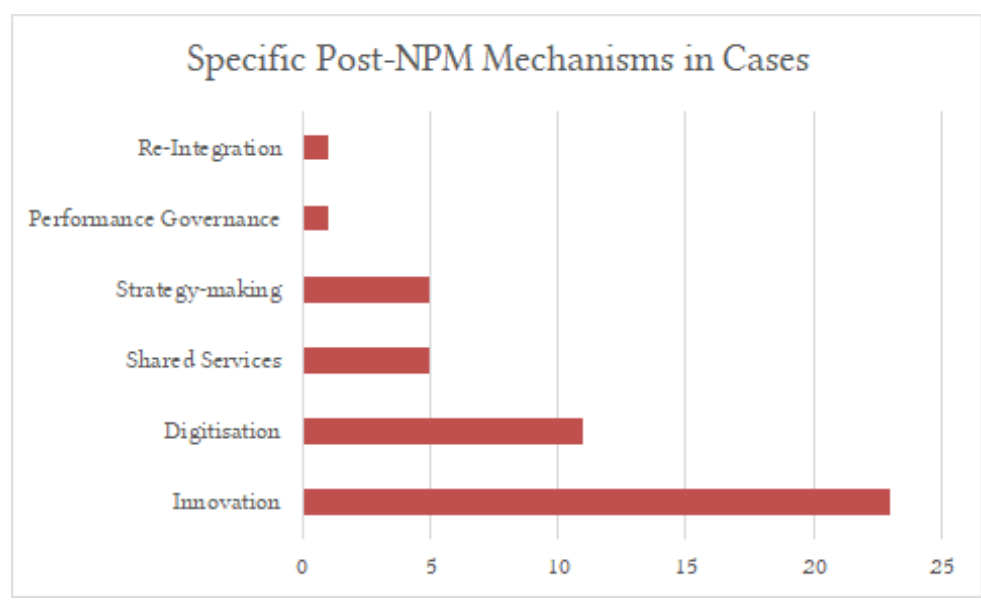

Figure 5: Post-NPM Mechanisms in Cases. 


\subsection{Synthesis of Findings}

Finally, we attempt to integrate our findings here to refine both our conceptual model and our initial theory of AI application in public sector presented in Section 2.3 (Figure 1) and 3.2 respectively. To refine the realist review framework, we establish the set of mechanisms corresponding to the four contexts in our model - post-NPM, organisational, individual and AI innovation. The mechanism corresponding to the postNPM context are provided in Figure 3. The mechanisms for the organisational and individual contexts were obtained by analysing the challenges in Table 5 as they capture important enabling factors at these two levels. The mechanisms for the AI Innovation level is obtained by summarising the specific AI technologies provided in Table 3. These technologies are associated with AI methods in Fig. 3. The resulting refined context-mechanism-outcome (CMO) model is provided in Fig. 6.
Finally, we present the specific case theories or propositions obtained from our study. The synthesis below is based strict alignment of the contexts, mechanisms and outcomes as presented in our cases expressed in Table 3. While the model in Fig. 6 shows the various mechanisms, it does not show which specific mechanisms are associated with a particular outcome. We constrain (or restrict) the relationships between the mechanisms and outcomes to enable the generation of a more accurate set of theories from our cases. The resulting theories are presented as strict CMO configurations in Table 6. The entries in the table could be read as follows. Consider the first entry, we have: by deploying "Machine Learning [AI Innovation] in digitisation, shared service or innovation context [Post-NPM environment], we should obtain improved service quality and time [Outcome]". Note that the chosen example does not have information on the organisational and individual contexts.

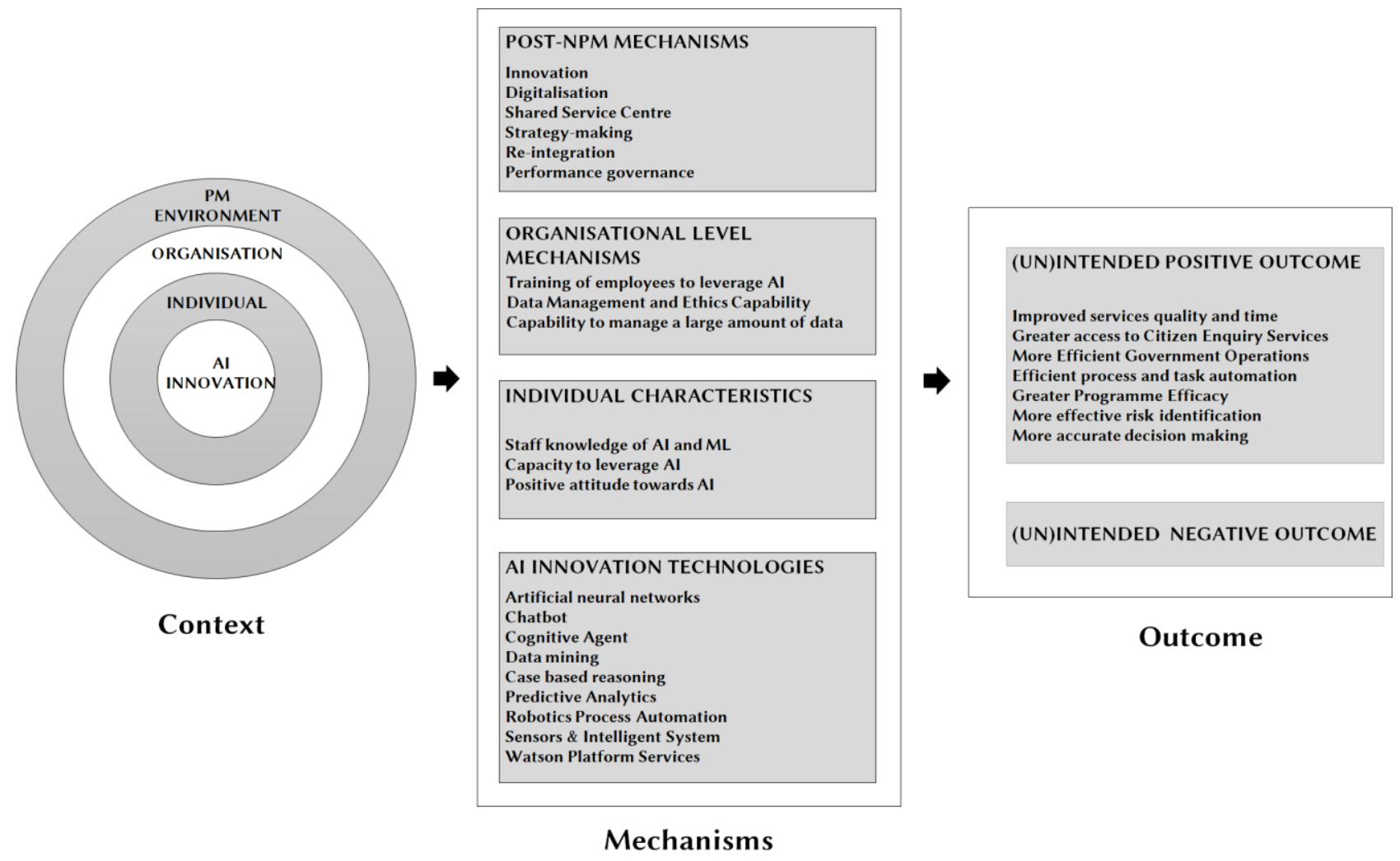

Figure 6: Refined Context-Mechanism-Outcome Model for AI in the Public Sector. 
Table 6: Resulting Context-Mechanism-Outcome Configuration.

\begin{tabular}{|c|c|c|c|}
\hline No & \multicolumn{2}{|l|}{ Antecedent } & Outcome \\
\hline 1 & $\begin{array}{l}\text { Post-NPM } \\
\text { Organisational } \\
\text { Individual } \\
\text { AI Innovation }\end{array}$ & $\begin{array}{l}\text { Innovation, Digitisation, Shared service centre } \\
\quad * \\
* \\
\text { Machine Learning }\end{array}$ & $\begin{array}{l}\text { Improved services quality } \\
\text { and time }\end{array}$ \\
\hline 2 & $\begin{array}{l}\text { Post-NPM } \\
\text { Organisational } \\
\text { Individual } \\
\text { AI Innovation }\end{array}$ & $\begin{array}{l}\text { Innovation, Digitisation, Shared service centre } \\
\text { Data management \& Ethics capability, Capacity to manage huge } \\
\text { amount of data } \\
\text { Ability to leverage AI } \\
\text { NLP }\end{array}$ & $\begin{array}{l}\text { Greater access to citizen } \\
\text { enquiry services }\end{array}$ \\
\hline 3 & $\begin{array}{l}\text { Post-NPM } \\
\text { Organisational } \\
\text { Individual } \\
\text { AI Innovation }\end{array}$ & $\begin{array}{l}\text { Strategy making, Innovation } \\
* \\
* \\
\text { Distributed AI }\end{array}$ & $\begin{array}{l}\text { More efficient government } \\
\text { operations }\end{array}$ \\
\hline 4 & $\begin{array}{l}\text { Post-NPM } \\
\text { Organisational } \\
\text { Individual } \\
\text { AI Innovation }\end{array}$ & $\begin{array}{l}\text { Digitisation, Innovation, Reintegration, Strategy making } \\
\text { Training of employees to leverage AI, Data management \& Ethics } \\
\text { capability } \\
\text { Staff knowledge of AI/ML, Ability to leverage AI, Positive attitude } \\
\text { to AI } \\
\text { ML, Distributed AI, Knowledge representation and reasoning }\end{array}$ & $\begin{array}{l}\text { Efficient process and task } \\
\text { automation }\end{array}$ \\
\hline 5 & $\begin{array}{l}\text { Post-NPM } \\
\text { Organisational } \\
\text { Individual } \\
\text { AI Innovation }\end{array}$ & $\begin{array}{l}\text { Strategy making, Innovation } \\
\text { Capacity to manage huge amount of data } \\
\text { Staff knowledge of AI/ML } \\
\text { Machine Learning }\end{array}$ & $\begin{array}{l}\text { Greater } \quad \text { programme } \\
\text { efficacy }\end{array}$ \\
\hline 6 & $\begin{array}{l}\text { Post-NPM } \\
\text { Organisational } \\
\text { Individual } \\
\text { AI Innovation }\end{array}$ & $\begin{array}{l}\text { Performance governance, Strategy making, Innovation } \\
\text { Employee training to leverage AI } \\
\text { Staff knowledge of AI \& ML, Capacity to leverage AI } \\
\text { Machine Learning }\end{array}$ & Effective risk identification \\
\hline 7 & $\begin{array}{l}\text { Post-NPM } \\
\text { Organisational } \\
\text { Individual } \\
\text { AI Innovation }\end{array}$ & $\begin{array}{l}\text { Digitisation, Innovation, Strategy making } \\
\text { Capacity to manage large amount of data } \\
\text { Staff knowledge of AI \& ML } \\
\text { Natural Language Processing, Machine Learning }\end{array}$ & $\begin{array}{l}\text { More accurate decision } \\
\text { making }\end{array}$ \\
\hline
\end{tabular}

\section{Discussion and Conclusion}

Our goal in this work was to carry out a systematic review based on the realist review tradition better understand how and why AI technologies have worked in reported cases drawing from the realist review approach. Our interest in this approach is based on robust evidence potential. As increasingly observed, traditional technology and innovation acceptance models such as Unified Theory of the Acceptance and Use of Technology [32] and Information Systems Success Model [33], [34] do not fully account for the different categories of factors to successfully adopt and use new digital technologies for specific benefits. According to Burton-Jones et al. [35] much of the technology adoption theories were developed in an earlier generation when we could think of distinct users employing clearly distinguishable systems, in bounded contexts. As time has passed, IT has become increasingly intelligent, interconnected, and infused through all our contexts, and these older theories have become increasingly ill- suited" [35]. Building on these past works, our approach in this study was to avert the shortcoming of traditional models while attempting to capture the contexts and corresponding conditions and factors (mechanisms) for successful AI technologies use in different public management and governance contexts.

Based on our findings, we are beginning to understand the potential positive and negative influences across the various contexts in which AI technologies could be deployed in the public sector. Both the conceptual framework and theories provide not only researchers but public managers plausible theories to guide their enquiries or programmes.

Another important consequence of our findings is in the claims of post-NPM conceptualisations. Our study here shows that are clear evidence that disruptive digital technologies such as AI are enacted within public management mechanisms associated with digital government era (both 1\&2) and strong public value management. We did not find any case in which AI was deployed within the NPG context. This may be due to the 
nature of AI solutions that are currently being deployed. This situation may change with time.

The co-occurrence between DEG and PVM mechanisms also point some form of convergence (or perhaps complementarity) between these conceptualisations. All these justify further research investigation.

\section{ACKNOWLEDGMENTS}

This publication has emanated from research supported in part by a research grant from Science Foundation Ireland (SFI) under Grant Number SFI/12/RC/2289, co-funded by the European Regional Development Fund.

\section{REFERENCES}

[1] H. Margetts and P. Dunleavy, "The second wave of digital-era governance: a quasi-paradigm for government on the Web Subject Areas: Author for correspondence:," Philos. Trans. R. Soc., vol. A 371, no. 20120382, pp. 1-17, 2013.

[2] P. Dunleavy, H. Margetts, S. Bastow, and J. Tinkler, "New public management is dead - Long live digital-era governance," f. Public Adm. Res. Theory, vol. 16, no. 3, pp. 467-494, 2006.

[3] C. Greve, "Ideas in Public Management Reform for the 2010s. Digitalization, Value Creation and Involvement," Public Organ. Rev., vol. 15, no. 1, pp. 49-65, 2015.

[4] E. A. Lindquist and I. Huse, "Accountability and monitoring government in the digital era: Promise, realism and research for digital-era governance," Can. Public Adm., vol. 60, no. 4, pp. 627-656, 2017.

[5] A. Ojo and S. Mellouli, "Deploying governance networks for societal challenges," Gov. Inf. Q., vol. 35, no. 4, pp. S106-S112, 2016.

[6] A. Clarke and H. Margetts, "Governments and citizens getting to know each other? open, closed, and big data in public management reform," Policy and Internet, vol. 6, no. 4, pp. 393-417, 2014.

[7] World Government Summit, "Best Government Emerging Technologies," 2017.

[8] The Federal Government, "Key points for a Federal Government Strategy on Artificial Intelligence," 2018.

[9] Europeam Commission, "Communication from the Commission to the European Partliament, the European Council, The Council, The European Economic and Social Committee and teh Committee of the Regions Coordinated Plan on Artificial Intelligence," 2018.

[10] Capgemini Consulting, "Unleashing the potential of Artificial Intelligence in the Public Sector," 2017.

[11] M. Halaweh, "Viewpoint: Artificial intelligence government (Gov. 3.0): The UAE leading model,” f. Artif. Intell. Res., vol. 62, no. June, pp. 269-272, 2018.

[12] P. Eggers, William D.; Schatsky, David; Viechnicki, "AI-Augmented government," p. 28, 2017.

[13] G. Stoker, "Public Value Management: A New Narrative for Networked Governance?," Am. Rev. Public Adm. Vol., vol. 36, no. 1, pp. 41-57, 2006.

[14] G. Stoker, "Public value management: A new narrative for networked governance?," Am. Rev. Public Adm., vol. 36, no. 1, pp. 41-57, 2006.

[15] S. P. Osborne, The New Public Governance - Emerging perspectives on the theory and practice of public governance. 2010 .

[16] E. A. Feigenbaum, "Artificial Intelligence Research," IEEE Trans. Inf. Theory, no. October, pp. 248-253, 1962.

[17] H. A. Simon, "Artificial intelligence: an empirical science," Artif. Intell., vol. 77, no. 1, pp. 95-127, 1995.

[18] M. L. Minsky, "Steps toward Artificial Intelligence," in Proceedings of the IRE, 1961, vol. 49, no. 1 , pp. 8-30.

[19] H. Mehr, "Artificial Intelligence for Citizen Services and Government," 2017.

[20] G. Ogrinc and P. Batalden, "Realist Evaluation as a Framework for the Assessment of Teaching About the Improvement of Care," 7. Nurs. Educ., vol. 48 , no. 12 , pp. 661-667, 2009.

[21] J. P. Wisdom, K. H. B. Chor, K. E. Hoagwood, and S. M. Horwitz, "Innovation Adoption: A review of thoeries and constructs," Adm Policy Ment Heal., vol. 41, no. 4, pp. 480-502, 2014.

[22] D. E. de Souza, "Elaborating the Context-Mechanism-Outcome configuration (CMOc) in realist evaluation: A critical realist perspective," Evaluation, vol. 19 , no. 2, pp. 141-154, 2013.

[23] G. N. Kouziokas, "The application of artificial intelligence in public administration for forecasting high crime risk transportation areas in urban environment," Transp. Res. Procedia, vol. 24, pp. 467-473, 2017.

[24] K. C. Desouza, "Delivering Artificial Intelligence in Government: Challenges and Opportunities," 2018.
[25] a H. W. Chun, "Using AI for e-Government automatic assessment of immigration application forms," Proc. Natl. Conf. Artif. Intell., vol. 2, pp. 1684$1691,2007$.

[26] IBM Center for The Business of Government, "The Future Has Begun: Using Artificial Intelligence to Transform Government," 2018.

[27] M. Madaio, O. L. Haimson, W. Zhang, X. Chang, and M. Hinds-aldrich, "Identifying and Prioritizing Fire Inspections: A Case Study of Predicting Fire Risk in Atlanta," in Bloomberg Data for Good Exchange, 2015, pp. 0-5.

[28] B. HEATON, "New York City Fights Fire with Data," Government Technology, 2015. [Online]. Available: http://www.govtech.com/public-safety/New-YorkCity-Fights-Fire-with-Data.html.

[29] X. Lhuer, "The next acronym you need to know about: RPA (robotic process automation)," McKinsey, 2016. [Online]. Available: https://www.mckinsey.com/business-functions/digital-mckinsey/ourinsights/the-next-acronym-you-need-to-know-about-rpa.

[30] M. J. P. de Vasconcelos, S. Sllva, M. Tome, M. Alvim, and J. M. C. Perelra, "Spatial Prediction of Fire Ignition Probabilities: Comparing Logistic Regression and Neural Networks," Photogramm. Eng. Remote Sens., vol. 67, no. 1 , pp. 73-81, 2001.

[31] J. Werley, "Jacksonville debuts high-tech streetlights - and they're watching you," Biz fournals, 2015. .

[32] V. Venkatesh, M. G. Morris, G. B. Davis, and F. D. Davis, "Management Information Quarterly," vol. 27, no. 3, pp. 425-478, 2003.

[33] W. DeLone and E. McLean, "The DeLone and McLean Model of Information Systems Success," 7. Manag. Inf. Syst., vol. 19, no. 4, pp. 9-30, 2003.

[34] S. Petter, W. DeLone, and E. McLean, "Measuring information systems success: models, dimensions, measures, and interrelationships," Eur. F. Inf. Syst., vol. 17, no. 3, pp. 236-263, Jun. 2008.

[35] A. Burton-Jones, B. Butler, S. Scott, and S. X. Xu, "Next-Generation Information Systems Theories Special Issue Editors Motivation for the Special Issue," no. March 2018, pp. 1-5, 2019. 